\title{
Beyond the Riverside: An Alternative Sustainable Vision for Khartoum Riverfront Development
}

\author{
Ibrahim Zakaria Bahreldin ${ }^{1,2}$ \\ ${ }^{1}$ Department of Urban \& Regional Planning, Faculty of Architecture \& Planning, King Abdulaziz University, Saudi Arabia \\ ${ }^{2}$ Department of Planning and Urban Design, Faculty of Architecture, University of Khartoum, Sudan
}

Received January 21, 2020; Revised March 25, 2020; Accepted April 19, 2020

Copyright $\bigcirc 2020$ by authors, all rights reserved. Authors agree that this article remains permanently open access under the terms of the Creative Commons Attribution License 4.0 International License

\begin{abstract}
The waterfront is the source of human civilization, culture, and the economy. A lot of beings depend on water for the life cycle in which humankind is no exception. Today, the entire human civilization is diligently associated with water areas such as rivers, seas, and oceans because they support sustainable transportation, habitat, and living. Such association is what brands waterfronts as one of the significant and useful urban regeneration concepts for cities and regions. Nonetheless, despite the attention has been assumed to Khartoum riverfront in the last two decades, the city is still unable to utilize it in terms of spatial capacities, environmental assets, and socio-cultural values. This article introduces a concept through which the riverfront assets of the city of Khartoum can be utilized and appropriated to improve the quality of it is riverfront. The objective of this paper is to provide a conceptual framework of riverfront development that is aimed at improving functional, socio-cultural, and environmental capacities of the city. This framework intended to make the Nile, and its tribunes the focus of daily life and maximize the interaction between the city and its water spaces. This concept is also expected to meet the escalating recreation demand, as witnessed by the rush on many new landscaped sites in different locations of Khartoum.
\end{abstract}

Keywords Waterfront Development, Mobility Integration, Khartoum Riverfront, Urban Regeneration, Khartoum

\section{Introduction}

Waterfront development has been a subject of worldwide significance due to its contribution to city development and regeneration. Many cities in the world started reimagining their relationship to the water as it provides many social, cultural, economic, and environmental benefits for the city, and its residents. With the current innovations and successes of waterfront development examples observed worldwide, this theme seems to have got a lot of attention lately as a tool for cultural, social, environmental, and economic revival. Khartoum, the capital region of Sudan is not an exception.

The city of Khartoum is branded as a city that lives with water (Bahreldin, 2003). The name of "Khartoum" itself is coming from the shape of the river as it arrives at the city in a form that epitomizes the elephant trunk or "al-Khartoum" in Arabic. The river was life-giving for Khartoum economy, culture, social life, and environment for many ages. However, after being ignored for several years, Khartoum started to cultivate its waterfront assets soon after Meffit 1977 plan and oil discovery in Sudan. Many projects were initiated, of which numerous are thriving while the majority are not. Unfortunately, South Sudan's succession in 2011 marked a new political and urban development era in Sudan and Khartoum Waterfront. Looking for alternative ways to support the surging country budget, Khartoum state has begun to exploit the city riverfront at an unprecedented rate. At this point, the waterfront developments were much driven by the rule of capital and investment need rather than socio-cultural and environmental requirements. Currently, Waterfronts in Khartoum city are rapidly transforming from space of interaction and social encounters to areas that exhibit the role of capital and the inadequate planning interventions (Abdel-Rahim, 2008; Bahreldin, 2003). This condition continued to dominate and shape the nature of waterfront development in the city in the past ten years and until today.

\section{Research Problems}

Historically the river Nile waterfront played an essential role in the cultural landscape of the Khartoum city 
residence (Refaat, 2015). Khartoum has been and still considered as a city that is produced by the water. Currently, Khartoum urban waterfronts are underutilized (Bahreldin, 2003) and excessively privatized (Abdel-Rahim, 2008), given that the waterfront development is becoming much driven by the rule of capital and investment needs rather than socio-cultural and environmental requirements of the city. Besides, tapping on the economic potential of the Nile and its riverfront as inclusive, ecological, and recreational zone, it should, therefore, be the subject of concrete and comprehensive study at the heart of the current Khartoum Structure Plan (KPP5) (Abdel-Rahim, 2008). In this sense, Waterfronts' development as a tool for sustainable urban regeneration seems to be underestimated in the Khartoum context. Hence, most of the previous and present attempts to develop the riverfront including the current KPP5 do not respect the development possibilities of such a valuable asset.

\section{Research Aims and Objectives}

This article introduces a concept through which the riverfront assets of the city of Khartoum can be utilized and appropriated to improve the quality of its riverfront. The main objective of this paper is to provide a conceptual framework of riverfront development that is aimed at sustaining the riverfront functional, social, and environmental capacities. This framework intended to make the Nile and its tribunes the focus of daily life and maximize the interaction between the city and its water spaces. This concept is also expected to meet the escalating recreation demand, as witnessed by the rush on many new landscaped sites in different locations of Khartoum.

\section{The Evolution of Waterfront Development and Urban Regeneration}

Much has been written about the phenomenon of waterfront redevelopment, often under the umbrellas of a broader urban regeneration or cultural regeneration strategies (Bruttomesso, 2006; Carta \& Ronsivalle, n.d.; Loures, 2015; Mostafa, 2017; Pereira, 2016). In Wrenn'
1983 book "Urban Waterfront Development," the emphasis was placed on the economic opportunities and public enjoyments of the waterfront sites. Wrenn utilizes tracing the historical evolution of urban waterfronts to provide several guidelines for future improvement. Post-2000 reviews of waterfront development by, for example, Waley (2007), (Moretti, 2008), and Sairinen and Kumpulainen (2006) have set the general policy debates from an urban regeneration perspective. More recent studies by authors such as Carta (2016), P. Yocom, et al., (2016) have provided a more contemporary view and framework of the waterfront paradigms and schools of thought. For instance, in his seminal work, The Fluid City Paradigm, Carta (2016) argued that the waterfront needs to be developed in terms of paradigm shifts to be able to produce more profound innovations, methods, tools, and visions. Carta, 2016: 6) provided three of what he calls "Paradigm shift" in urban waterfront regeneration. These paradigms are listed as:

1. The first generation of waterfronts is "a leisure-based regeneration." Such generation is characterized by the focus of the urban development agenda of waterfront on the recreation aspects of the waterfront. An excellent example of this generation is suggested by Carta (2016) in Baltimore.

2. The second generation is based on "cultural and service investment." From how it is named, this generation utilizes space culture and site qualities as tools for investment. An excellent example of this typology is Barcelona.

3. Finally, the third generation of waterfront, which Carta identified as "waterfront 3.0," has to be, creativity-driven, able to produce a whole regeneration force for the city competitiveness as well as smartness and quality. Besides, for Carta (2016), the "Waterfront 3.0" can provide most of the characteristics of the first two types of waterfront.

Furthermore, Carta, (2016:6:7) provided an asset of seven guidelines that can lead the way of the waterfront 3.0. Those guidelines are; the identity principle, the economic sustainability principle, the potentiality principle; the dynamism principle; the interaction principle, the multisectoral principle, and the perturbation principle.

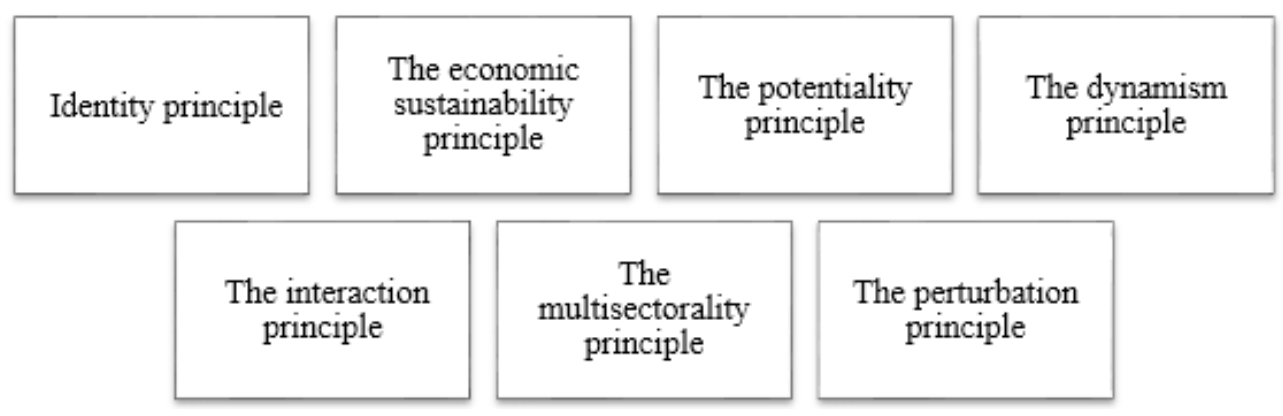

Figure 1. The seven guidelines for "Waterfront 3.0". Adapted from Carta (2016:6-7) 
Today the degree, speed, and scale of waterfront regeneration projects and associated development continue to stimulate and form a framework for many regeneration initiatives. Throughout the last two decades, the evolution and success of such projects have been phenomena that inspire many cities. Numerous waterfront sites have produced entire new city districts, quarters, and activities. Major waterfront development projects in Hong Kong, such new Kowloon Cultural Quarter, Singapore's Marina Bay, and Abu Dhabi's Cultural Quarter, are remarkable modern-day examples. Lots of these waterfront urban regeneration and development projects have been acclaimed as sites of prospective, critical territorial blocks for urban growth strategies in the twenty-first century. Smaller but very well admired models of waterfront development range from the uncovering and re-invention of the Cheonggye River in the center of Seoul to Sabarmath Riverfront Project in Gujarat and Brisbane's Riverfront Regeneration Project and the housing and commercial redevelopment of the London Docklands.

Acknowledging the massive literature on waterfront development, the research on this topic, however, takes a narrower focus: it concentrates on the disappearance of industrial and transport zones from the water's edge and on the new forms of land use, as well as on the practices of renewal (Tolnai, 2018). Such observation generally contradicts Carta's (2016) waterfront paradighm shifts as it encapsulates all the three paradigms under the umbrella of urban renewals regardless of the utilized approach. In other words, the three paradigm shifts delivered by Carta (2016) are seen as different facets of the process of urban renewals that are triggered by the lack of industry and transport zones in the waterfronts.

Nonetheless, a prevalent theme in these pieces of literature is showcasing examples from North America, Europe, and Asia. African waterfront development is, therefore, still lag. Thus, the three generations of waterfront development established by Carta (2016) might seem geographically oriented towards North American and European cities but not necessarily replicate the state of Waterfront in African cities. This article is, therefore, an attempt to dwell on this gap of the literature on the African context.

\section{Description of Khartoum City}

The character of Khartoum city is strongly determined by its geographical location. Favored with an exceptional location at the confluence of the White and Blue Nile, the city has been previously described as a center where many, and various forces meet (MEFFIT Consultancies, 1973). A vast populated desert and savannah surround Khartoum. The main structural element in Khartoum is the River Nile and its tribunes, the Blue and the White Niles that goes through the country for thousands of kilometers. Khartoum has an exceptional location at the confluence of the White Nile and the Blue Nile, shapes the river Nile.

Khartoum waterfront comprises of six riversides that span across three cities for more than $200 \mathrm{KM}$ (Meffit and Centics, 2008). This waterfront is by far the most extensive riverfront in Sudan. Due to the desert nature of Khartoum, urban development tends to cling to the Nile, which is running due North. Khartoum, therefore, took an elongated shape and grew extensively long (Wit, 2008). For the city of Khartoum, the Nile is not only a dominating structuring element but also a live generator and a divider. The Nile and its tribunes divide Khartoum into three different cities known as "Khartoum, Khartoum North, and Omdurman, as shown in Figure 2.

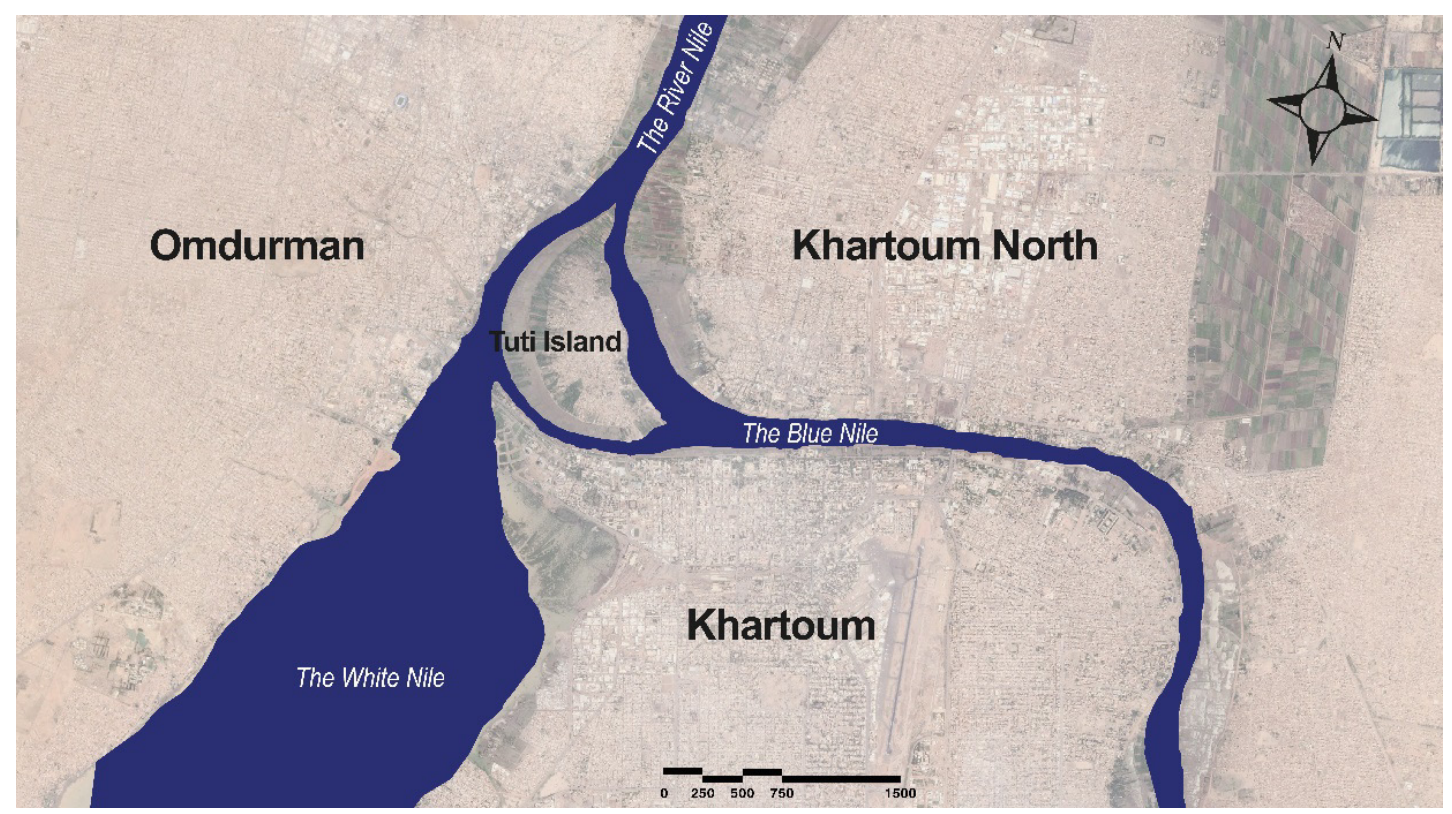

Figure 2. The composition of Khartoum central riverfront and the Nile confluences 


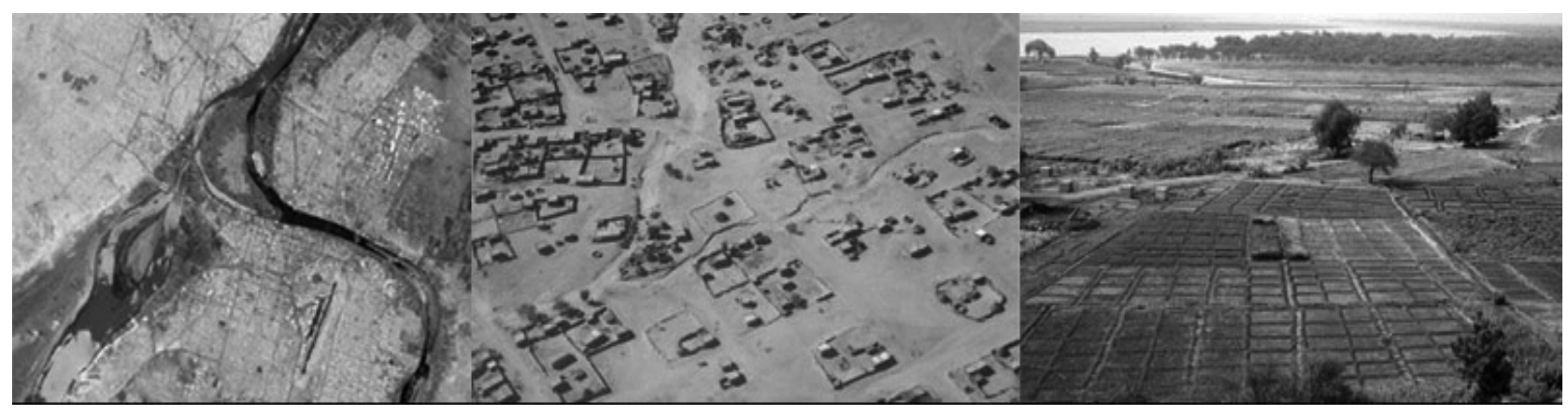

Figure 3. The components of the quality of place in Khartoum; The confluence of the white and the Blue Nile to the left, The vast desert at the middle, and the quality of landscape "the urban agriculture" to the right

\section{The Nature of the City of Khartoum and It Is Riverfront Development Challenges}

The literature on the quality of place in Khartoum city has been very much focusing on the quality of the urban landscape in Khartoum. Such scenery is reinforced by the confluence of the blue and White Nile (El-Kheir, 1991; Norberg-Schulz, 1984), the vast and immense desert (Bahreldin, 2003; Norberg-Schulz, 1984), the living experience that integrates nicely to the nature of the riversides (Refaat, 2015), and the quality of the urban landscape and urban agriculture that is rapidly disappearing now (Marina d'Errico, 2015; Norberg-Schulz, 1984). The above four components, as shown in Figure 3, represent what we can call the elements of the quality of place in Khartoum riverside.

During the last two decades, the quality of the Khartoum landscape is rapidly disappearing, following an excessive urban development practice observed in the city riverfront. For instance, many of the civic agricultural activities seen in Figure 3 has been replaced by major urban development projects or significant transportation roads. This change is aggravated by the increase of activities of Khartoum Centre, which in turn increased the mobility requirements along the riverside. Unfortunately, the observed changes resulted in a decrease in public activities on the riverside. For instance, al-Mogran "the confluence" park was privatized and eventually closed since 2006. Six of April park was fenced and transformed into a paid park. The famous and historical al-askila coffeeshop was also shut down, among other activities. The open beach in the "Burry" neighborhood was transformed into dense private urban development projects, including the National club, TARA city investment Project, and the massive Dawhat al-Neel project. In Omdurman, the vast urban agriculture along the river Nile was rapidly converted into private restaurants, coffee shops, and wedding halls that have created severe traffic congestion on Nile Avenue. Large urban development projects in Omdurman waterfront are also observed, such as al-Nur city and "Madinat al-mal wa al-aamal." Khartoum north was also terrain for such interventions, including the massive urban development project such as the "Musherib" project and the Blue Nile city in the east of the city.

The current landscape changes are characterized by the loss of diversity, coherence, and identity of the existing landscapes (Antrop, 2004). Such spatial changes generated several functional and environmental challenges to the city, including the loss of the fertile land and increase of the river follow, which eventually led to the process of landslides and sedimentation. The sum of those challenges draws a very grey picture of the future of the publicness of the access and utilization of the riverfronts in Khartoum city. Also, similar to most of the riverside cities in Sudan, Khartoum, suffers from the yearly flooding and extreme run-off that strikes during the rainy seasons. Several neighborhoods and urban development activities are affected every year by this. Fortunately, there are still some open green spaces and urban agriculture that serve as flood absorption zones like al-Sunut forest and the agriculture land in Tuti Island.

\section{The History of the Riverfront Development in Khartoum}

Around the world, riverfront development and regeneration was a significant planning phenomenon in the last decades of the twentieth century. In Post-2010, Khartoum Waterfront continues to attract considerable interest in different forms. Khartoum is considered as one of the most planned cities in Africa (Marina d'Errico, 2015). The city has gone through five previous master plans since the country's independence in 1956. Unfortunately, none of them have been successfully implemented (Hamid \& Bahreldin, 2013b). The failure of implementing those plans is related to that the plans themselves are not realistic (Mustafa Ahmad, 2000), lack of funds (Hafazalla, 2008), inadequate commitment to realize the plans, and poor participatory practices on those plans (Bahreldin, 2013).

Several studies have previously covered the issue of Khartoum riverfronts' development and riverfront regeneration. While most of these studies focused on providing historical traces of the riverfront (Alliance of Political power in Tuti, 2007; Hamid \& Bahreldin, 2013a; 
Ibrahim \& Davies, 1991; Idrees, 2008), not many do provide insights in the future of the riverfront development and how it should be envisioned. Examples includes studies done by Abdel-Rahim (2008); Bahreldin (2003); Bahreldin \& Hamid (2018).

In most of those studies, it was pronounced that the riverfront, though, was very much integrated into urban city development and economic and social life; they were not directly affected by the planning intervention until the Meffit plan of 1977 in which control on the riverfront buildings heights was enforced. Besides, the Meffit plan suggested building a viewing tower at the edge of the "al-Mogran" the Nile confluence point in Khartoum. After the oil discovery in Sudan, Khartoum riverfront has started a new wave of urban transformation in which many high-rise towers that resemble the "Dubai" urban development model have been initiated (Franck, 2016). Among those projects is the famous al-Sunnut Project (Figure 4), which is still struggling to date to be finalized. The second Doxiadis plan has apprehensively studied riverfront development. Doxiadis plan did not provide a consolidated vision for the riverfront. It was until the current structure plan (2008-2033) that the riverfront has finally got a very dedicated urban development program and development guidelines. This program divides the Khartoum riverfront into thirteen zones, of which each has various development strategies and regulations (Khartoum Structure Plan Implementation Directorate. MPPU, 2013). Unfortunately, although the current structure plan (KPP5) is still on it is the second stage of implementation, many of the riverfront policies enforced become obsolete, especially in the Khartoum Urban zones. Accordingly, following the South Sudan succession and the subsequent drain of the government budget, the exploitation of waterfront land and land uses in contemplation of funding the city surging budget become a trend. Under such conditions many of the new urban development in Khartoum city does not respect the urban framework suggested by KPP5, creating completely imbalanced and uncontrolled, very privatized riverfront.

Unlike waterfront developments in many common examples, Khartoum waterfront today is still under it's the initial development stage. Khartoum waterfront has not yet reached the stage of decay or derelict. However, the process of Waterfront in Khartoum witness a novel turn between 2008 and 2018, in which the waterfront has undergone massive transformation attempts. Historically subjugated by uses of agriculture, fishing activities, boat industry, shipping, and transportation, intense economic modernization in the twentieth century abandoned many of these once productive spaces, leaving behind large strips of derelict and degraded land, high-speed streets private spaces, and low-density residential communities. Today, it is well observed and documented that Waterfront in Khartoum become commonplace of neo-liberal agendas and modernization, on top of a strong presence of the role of capital over the sustainability of the place (Bahreldin, 2020; Franck, 2016).

This rather short review shows that most of the master plans since the first Doxiadis plan for Khartoum did not respect the "Genius Loci" of this unique location as characterized by the linearity of its natural flowing rivers. The Genus Loci suggest linear planning congruent with the linearity of the waterways by considering the Nile as a potential linking channel rather than a barrier (Abdel-Rahim, 2008).

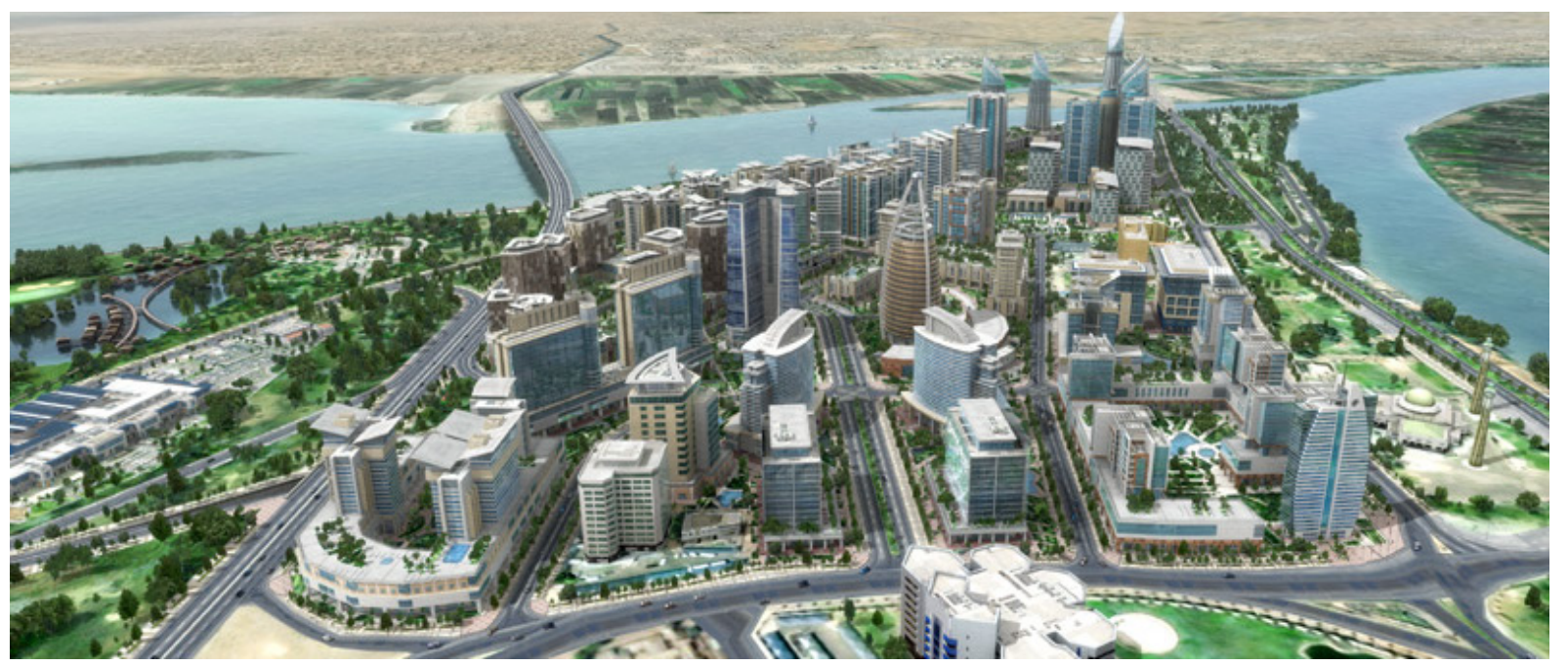

Figure 4. al-Sunnut Project, one of the major urban development projects in Khartoum riverfront that is still struggling to be achieved due to unrealistic planning and lack of funds 


\section{Types of Riverside Spaces in Urban Khartoum}

The typologies of waterside in Khartoum are an essential part of this study. The nature of the water edge identifies methodologies and techniques for further improvement. Recognizing the quality of the place is critical as it helps to develop the area about how people interact with that place. Our study of thirty-one different locations along the riverside seen in Figure 10 found out that there are generally four dominant types of water fronts, those are:

\subsection{The Water-edge}

In this typology, there is always land-to-water access. Buildings rise straight at the edge of the water representing an intermediate lace between water and the city. Several examples of this typology can be identified in Khartoum riverside, such as the traditional defense wall built during the al-Mahadeiya in Omdurman "al-Tabia," the open recreational space and restaurants in the al-Mogran area (currently under regeneration), the recreational area and restaurants in Khartoum city riverside and Khartoum North residential neighborhoods bordering the North waterfront of the Blue Nile and finally down-stream of the white Nile in al-Kalakla neighborhood. The composition of this typology is shown in Figure 5.

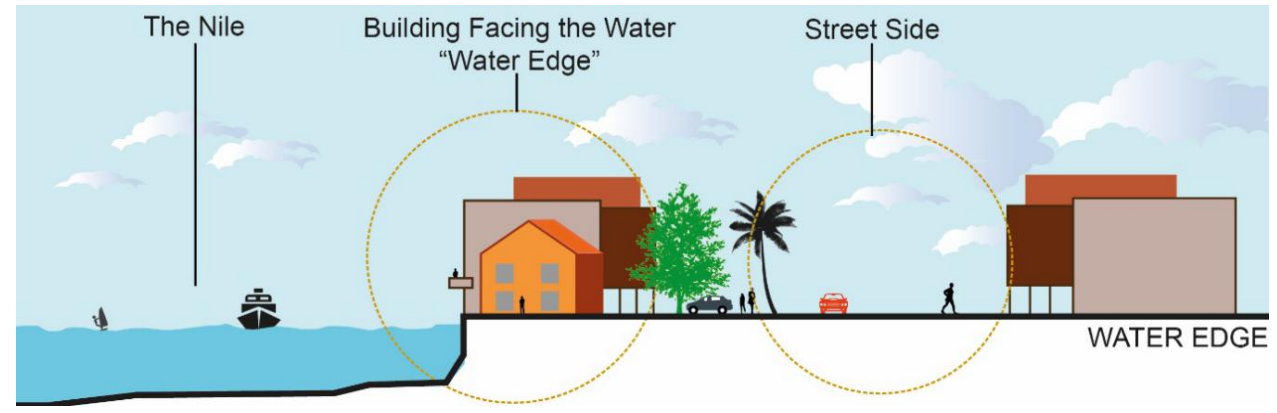

Figure 5. The Water-edge typology in the riverside

\subsection{The Perforated Water Edge}

This type generally provides active contact with water through a perforated passageway or terraces that act as access to water, regardless of whether this access is private or public (Figure 6). Some examples of this typology include "Feincia" restaurants, some of Kafoury residential areas, as well as some of the farmland in the Soba area in Khartoum.

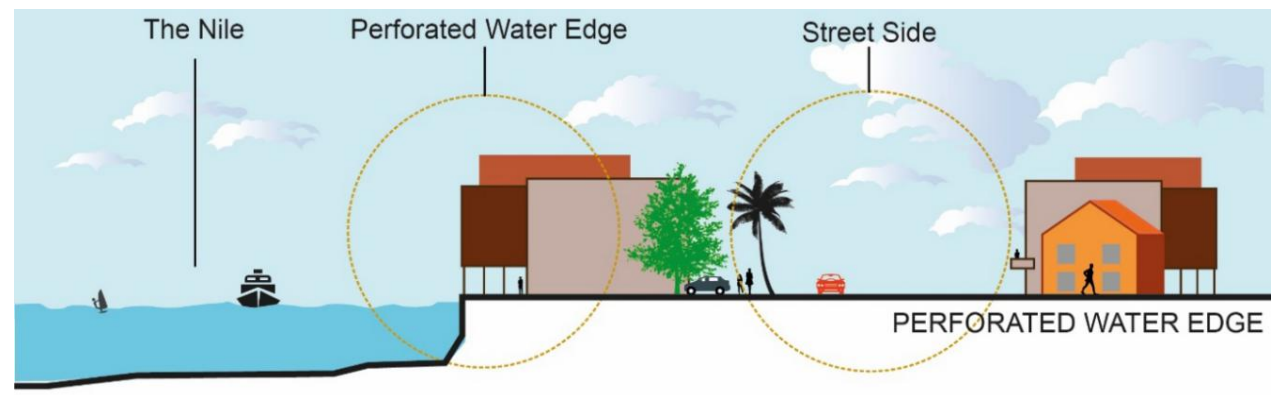

Figure 6. The Perforated water edge typology

\subsection{The Setback Building}

This typology, which is exhibited in Figure 7, is the most common water-building relationship observed in Khartoum, Omdurman, and Khartoum North. In this typology, the space between the building and the water varies from the narrow passageway to a wide fast street, i.e., the Nile Avenue in Omdurman, Khartoum and Khartoum North. Recently, this typology is actively promoted in urban Khartoum through the current waterfront development guidelines stated by the new Khartoum Structure Plan (2008-2033), through which a walkable corridor was mandated between the building and the water line or the protection line. 


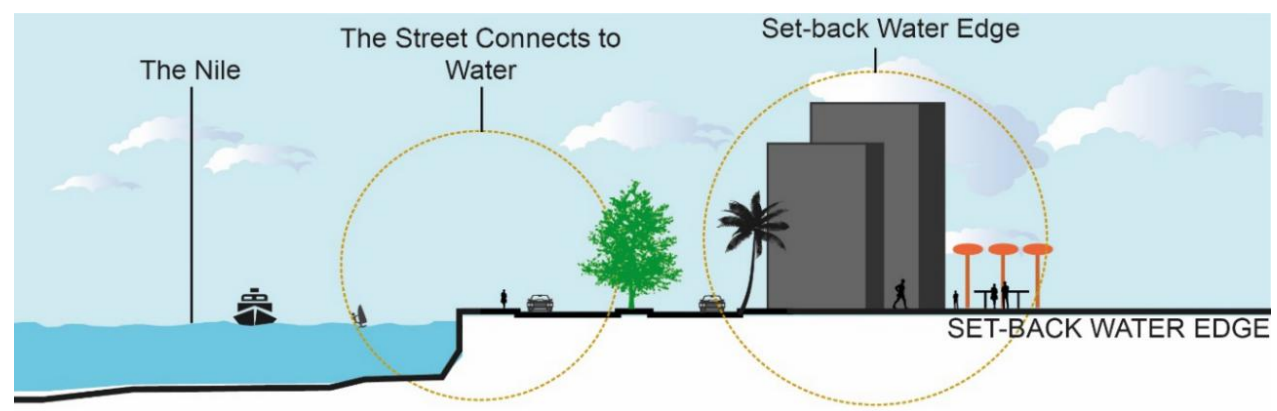

Figure 7. The Setback building typology

\subsection{The Riverbank/ or Beach}

This typology was very common in Khartoum until 2011 when the South of Sudan seceded, leaving a considerable income deficit due to the loss of the oil in the country's yearly budget. After the secession, the waterfront land was extensively exploited as an alternative income generator for the state. Such typology exhibits that the water edge was not widely utilized by urban development. Therefore, it is dominated by urban agriculture and open beaches. This typology, which is shown in Figure 8, is mostly observed in the White Nile riverside in Omdurman and the river Nile front in Shambat in Khartoum North due to the slower water run-off, which allows for sedimentation and therefore fertile agricultural lands.

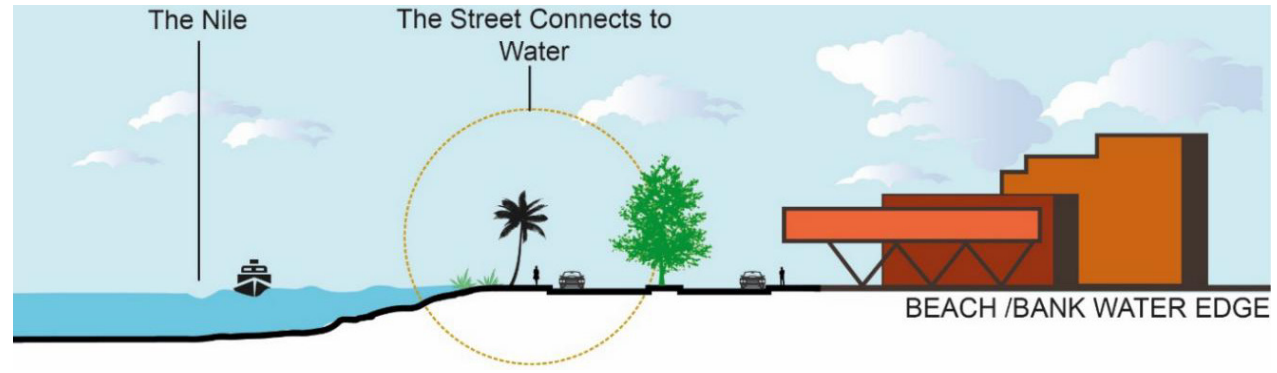

Figure 8. Bank/Beach waterside typology

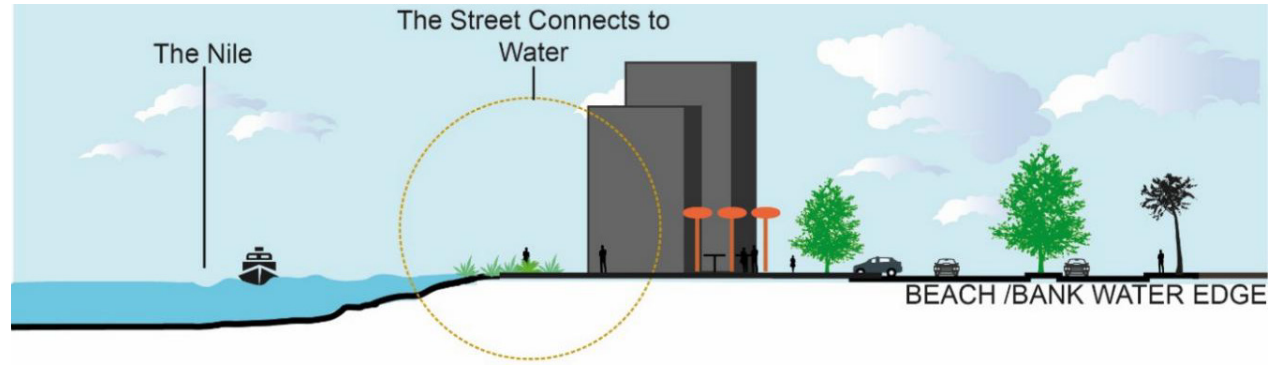

Figure 9. Bank/Beach waterside typology/2 


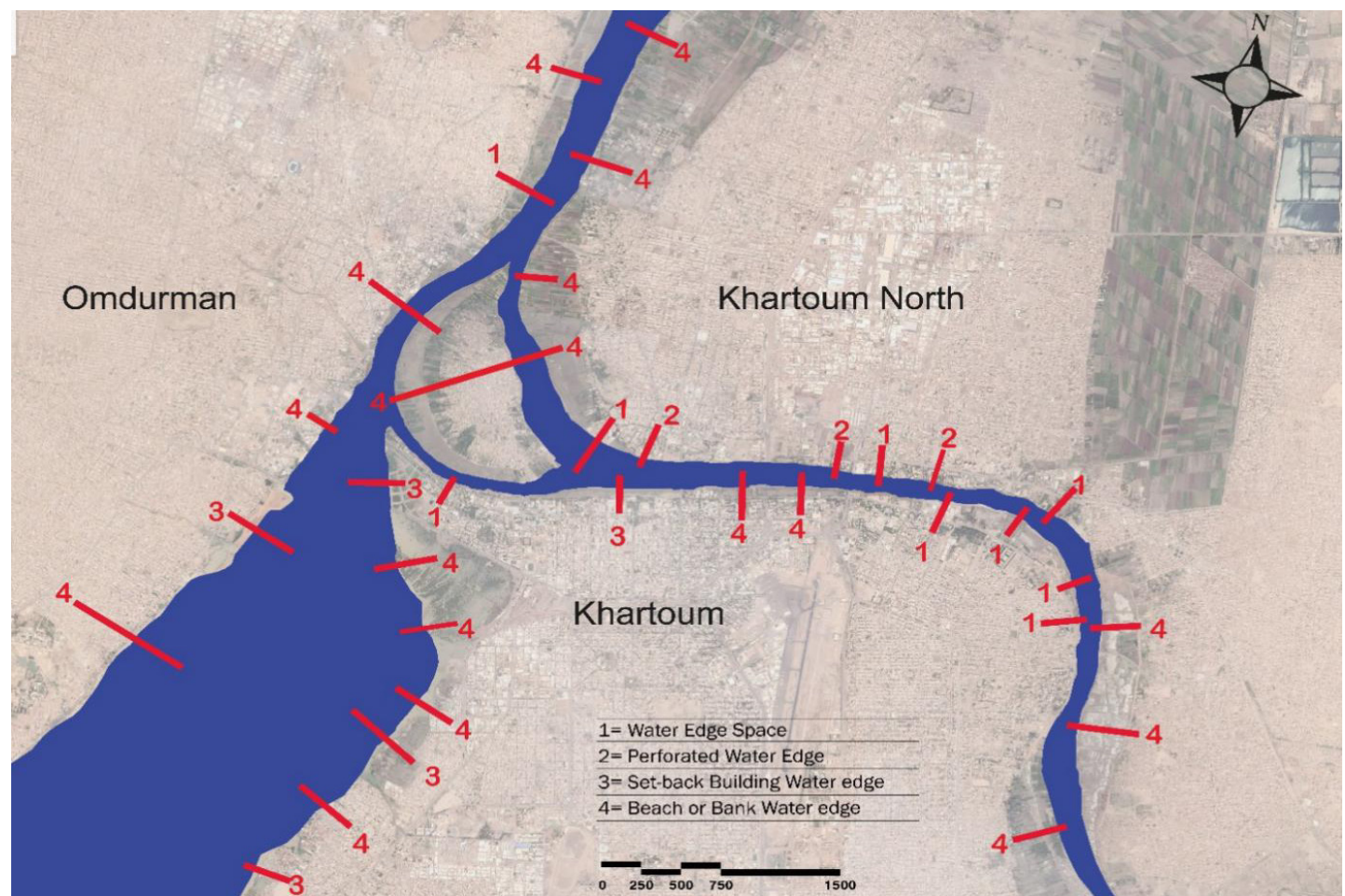

Figure 10. Types of riverside spaces along Khartoum riverfront

Figure 10 exhibits all the four typologies of the waterfront observed in Khartoum. At this point, it must be noted that even after the last Khartoum Structure Plan (2008-2033), which suggests a massive urban change to riverfront structure, the previous two typologies exhibited above are still dominating the current waterfront typologies. Such observation suggests that the urban development typological change in the waterfront is gently shifting from one typology to another. Also, it is noteworthy that the slow implementation of the KPP5 has given the riverfront development better opportunities to utilize its potential as KPP5 has generated massive exploitation of the natural and cultural assets of the waterfront.

\section{Khartoum Riverfront Sustainable Urban Development Vision}

The vision presented in this article is built to safeguard the environmental, natural, and socio-cultural assets of Khartoum waterfront. Utilizing Carta's (2016) waterfront 3.0 guidelines as a benchmark, this vision aims at;

1. Increasing the public access to riverfront (connectivity) for all city dwellers as well as the visitors including the tourists;

2. Activating the riverfront using a diverse mix of land uses that nicely integrates with the existing functional character of the place;

3. Supporting and encouraging economic activities related to riverfront and rivers:
4. Restoring the quality of riverfront in places where they have been lost and protecting affected areas;

5. Linking riverfront to the surrounding ecosystem and water system in Khartoum;

6. Integrating the development of riverfront with urban resilience management to reduce the unwanted effects of floods and floods, and

7. Improving water quality with biodiversity.

To comprehend the above mentioned seven goals, it is necessary to provide a set of principles and strategies that can bridge the gap between the vision and it is application.

\subsection{Sustainable Riverfront Vision Principles}

The sustainable waterfront development vision addresses issues such as habitats, cultural heritage preservation, water management, and energy and resource conservation. To strategically locate the above mentioned Development vision into an implementable plan, urban development principles and strategies are necessary. Hence, the proposed concept for sustainable Khartoum riverfront development is grounded on five main principles which are;

1. Creating vibrant waterfront districts and neighborhoods by connecting the river to the city's residential quarters. Such a connection can be attained through;

- $\quad$ Strengthening the center of the city by focusing on the provision of an active link between the center and the riverfront. 
- The creation of new residential and commercial areas along the river, connecting the water to the rest of the city, and bringing the more active program to water space such as housing.

- The establishment of prominent public spaces, natural places, and orienting new urban development towards the riverfront.

2. Envisioning the riverfront as an active, livable public place. Such a strategy can be attained through;

- Enhancing recreation functions by providing new facilities and improving the existing ones.

- Programming new functions on the riverfront that can enhance the nature of activities happening there.

- $\quad$ Bridging between the old traditional settlements (Tuti Island) to Khartoum riverfront by an active water-based mobility system.

3. Connecting the riverfront to the rest of the inner city and the two other cities (Khartoum North and Omdurman) in a concept that resembles the waterfront as city front yard.

- Understanding to the city as a typical Sudanese house, with an active front yard. The riverfront act as a typical Sudanese front yard where most of the activities happen there.

- Encouraging a water-based mobility system that could be combined with the existing mobility system.

4. Generating a clean yet, accessible riverfront that can safeguard the ecological systems in Khartoum city. This ecological concept can be realized through;

- $\quad$ Protecting the al-Sunnut forest the only natural forest that remains from the old natural features in Khartoum center.

- Reducing water pollution from the land used adjacent to the riverfront

- Providing sustainable solutions for flooding challenges through understanding the city water system holistically.
- Encourage environmentally friendly buildings, techniques, and design interventions.

\subsection{General Development Strategies}

To realize the above-stated vision, it is necessary to translate the above-suggested vision into development strategies. Based on the five principles showcased above, we propose three sets of spatial policies that are expected to safeguard the vision provided earlier. These strategies are;

a) The mobility strategy which aims at utilizing the river as a central spine.

b) Open and public spaces strategy aims at improving the nature of activities as well providing environmental quality of the central waterfront.

c) The Landscape strategy which aims at improving both the perceptual and environmental impacts of the waterfront development.

\subsubsection{The Mobility Strategy "River as a Spine"}

The mobility strategy is the core development strategy of this vision. This strategy is centered at considering the Nile and it is tribunes as a longitudinal spine that connects the whole city through an active water-based mobility system (Figure 11). The nodes where transit occurs are also strategic places of intervention. The locations of the transit nodes can be strategically identified through a participatory approach in which a broad spectrum of stakeholders, including citizens, public sector, local governments, landowners, and transportation chamber, participate in identifying, assessing, and prioritize development issues related to that specific node. The participatory decision-making approach will ensure a collaborative identification of crucial interchange nodes along the riverfront as well as the functional typology/character of respective nodes. The proposed activity plan allows for a knowledge-based method of integrating the existing mobility structure on selected nodes to the proposed water-based mobility. The activity plan suggests initiating and developing projects on those identified transit nodes to connect the water to land modes of transport through public parks. The nature of those public parks is defined by the type of functional activity identified previously through the participatory decision-making mechanism. 


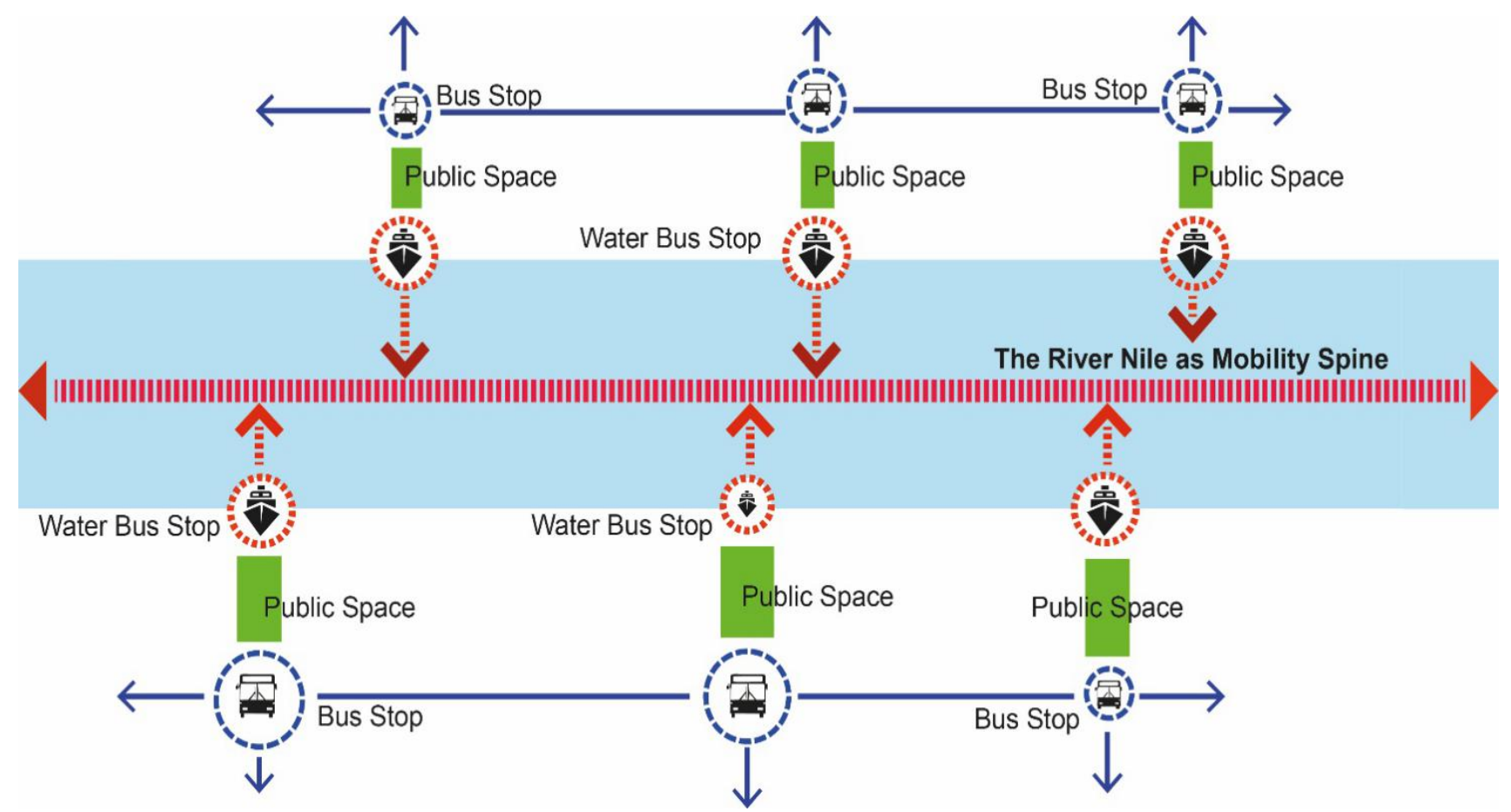

Figure 11. The River as Water spine that connects the city

The proposed mobility strategy shown in Figure 11 is established on improving the existing tourist kind of water-based transport into a robust transportation network that connects all the city through a gate to water. This system does not intend to work in a vacuum; instead, it is a system that should sync with the existing land-based transportation system (buses, bicycles, and trains). The two systems are envisioned to integrate through the transit nodes. Each one of those transit nodes is viewed to have its eccentrics that reflect both the identity and the quality of that place by enhancing its character and improving the existing functional, environmental, and socio-cultural values.

Based on the "river as spine" strategy, we have surveyed the riverfront slightly beyond Khartoum Centre. The results of our survey shown in Figure 12 suggest variable dominating functions and activities range from educational, heritage, recreational, administrative, and commercial functions. Those functions can be actively utilized to develop the transit nodes mentioned above. 


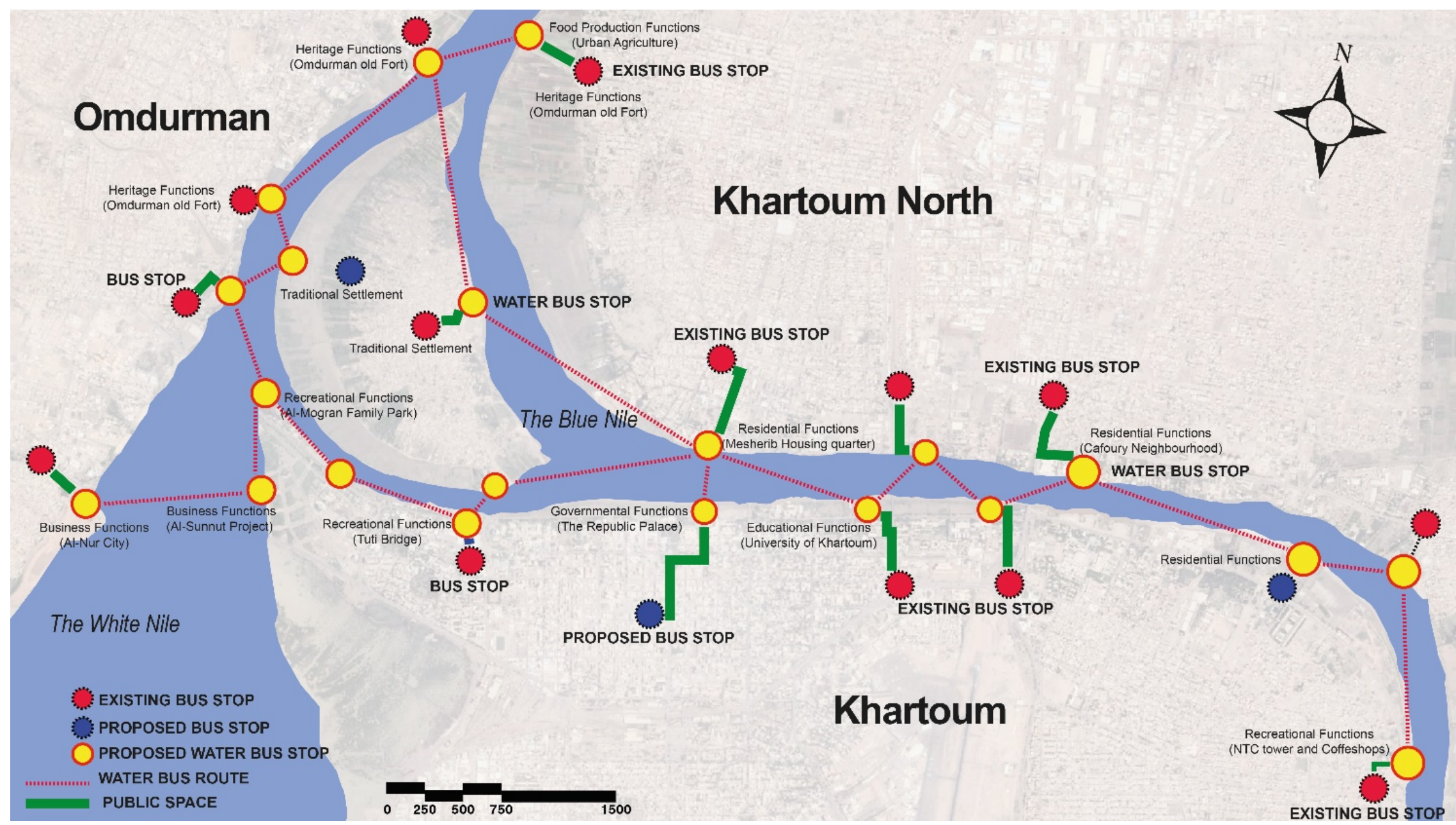

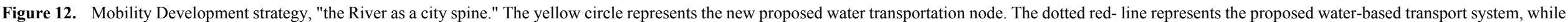
the Green line shows the connection between the transit nodes and the inner-city structures through public spaces. 


\subsubsection{Open and Public Spaces Strategy}

Public spaces are a critical asset to our cities. They deliver citizens many prospects to come together and engage with the community. Therefore, public spaces are considered as sites where the community comes alive, where connections among citizens are reinforced and where a sense of belonging is cultivated. They are also the terrain that sparks economic development and drives environmental sustainability. If public spaces are well-off, they are inclusive of the diversity of groups present in our cities and create a social space for everyone in the society to participate.

In this regard, the proposed open and public spaces strategy is centered on the utilization of public spaces as centers of engagements and transit zones, "connectors" between the proposed water mobility system and the existing "land-based" mobility structure. In this regard, the structure of the proposed public spaces is determined by the direction of movement from the water bus stop to the existing land-based bus stops and vice-versa, as shown in Figure 13. Along this route, several new functions are suggested to be injected to foster and strengthen the function typology and the character of the node. The open and public strategy is seen to sync nicely with the landscape strategy to improve the experience of users transiting from one station to the other.

\subsubsection{The Landscape Strategy}

Landscape planning and design is an emerging practice in Sub-Saharan Africa, and "there are rising opportunities for landscape architects to influence built and natural environments...in Africa" (American Society of Landscape Architects, 2011). In a city that is favored with extreme heat and dust "Haboob," urban landscape can be utilized as essential structuring elements. The urban landscape can create spaces that illustrate an environmental and social impact in Sub-Saharan Africa (Patterson, 2015). Therefore, considering both the cultural and ecological values of the landscape, our proposed landscape strategy, as shown in Figure 14, is based on utilizing landscape as; 1) space definer and divider; 2) as an environmental filter, and; 3) as a typological connector.

Utilizing landscape as space definer includes the use of plantation to define the edge of the existing and the new programmed public spaces. Besides, using landscape as an environmental filter includes utilizing landscape to create visual corridors that link the city to the water as well as using the green landscape to block the dust and reduce the space temperature. Utilizing landscape as a typo-connecter includes the use of landscape elements to generate a connection among the three different buildings typologies that exist along the riverside.

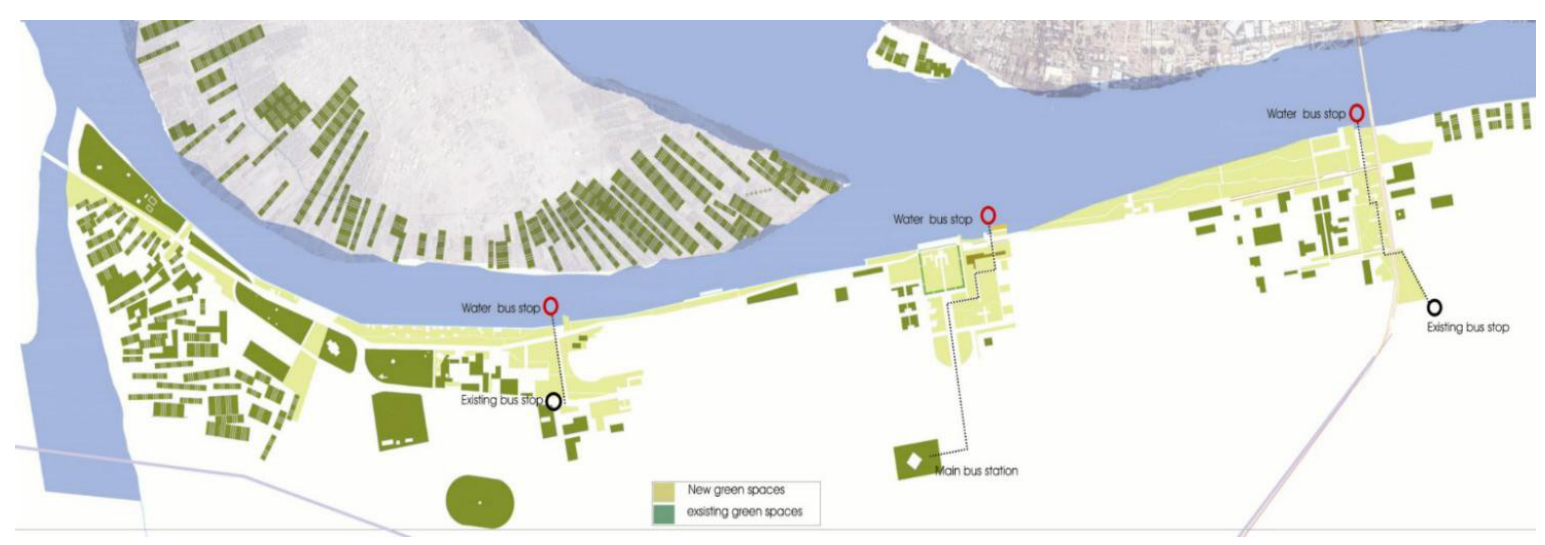

Figure 13. Open and public space development strategy

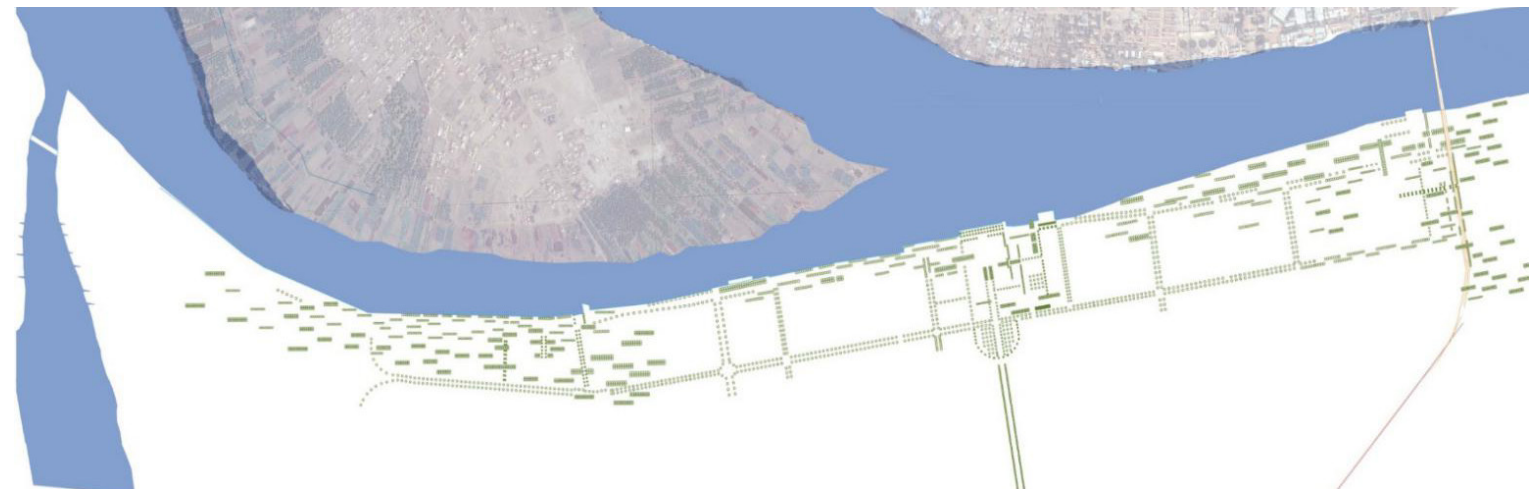

Figure 14. Landscape Development strategy shows plantation as space definer and functional integrator 


\section{Conclusions}

This article delivered a vision of the waterfront development in Khartoum city in the light of the current thinking about the potential of the waterfront in contributing to more sustainable city development in the future. The proposal provided is neither comprehensive nor participatory, yet, it offers clear strategic points of view that would help practitioners and policymakers in building a more inclusive public riverfront that safeguards the environmental and socio-cultural qualities of the city and water. Also, the concepts exhibited protect the Nile as a potential networking waterway. This connectivity is necessary if we are to prepare the Nile as the focus of daily life for the citizens of the three towns.

The proposal delivered fosters to break the vicious circle of concentric planning, which drives further regarding the desert and away from the Nile and reverts to compact linear development more congruent with the linearity of the Nile. We believe that the proposal exhibited cater for three interconnected typologies of riverfront including

1. The natural riverfront which includes natural waterfronts, beaches, wetlands, wildlife sites, critical water system, and water itself.

2. The public riverfront which contains the public parks, water sports, playground, and walkways;

3. The productive riverfront. This concept provides the encouragement of the riverfront activities as an economic opportunity by increasing not only the investment but also activities like urban agriculture, water transports, fishing, and all water-supported industry, i.e., boat manufacturing.

In addition to the above typologies, the proposed vision does incorporate all the four design attributes of sustainable riverside developed by (Liu, 2013). For instance, in terms of the "functional attributes," the vision exhibited provides mixed land uses and various amenities, in addition to affordable housing for low-income groups to promote social equality. The proposal also fosters employment opportunities that target low-income people and inner-city residents.

From the "accessibility" perspective, the proposed vision provides a public transit system that connects the city core to the peripheries through the waterfront. It also establishes a water-based transport system that is coupled with access and view corridors to the riverfronts. Also, the proposals provide pedestrian and bicycle paths to connect local trails to reasonable intervals and wayfinding. In terms of "cultural heritage and history," this vision suggests the utilization of the cultural values of each of the transit nodes in a way that connects the historical functions of the space to the waterfront in addition to introducing several cultural amenities, i.e., theatres and museums to space. Last but not least, from the "ecological" perspectives, the vision does protect the natural features of the waterfront such as the "al-Sunnut" forest in addition to preserving the natural habitat of the wildlife observed there. Also, the design interventions support stormwater management through permeable pavements, bio-swale, and the introduction of the wet-land during the floods. Urban agriculture also plays a vital role in ecological education as well as flood mitigation.

In conclusion, riverfront is essential component of the urban regeneration of cities. It is continually used as an element that re-establishes the physical links between parts of the city. We argue that the sustainability of any riverfront development should address these three activity typologies mentioned above as well as the four design attributes.

\section{REFERENCES}

[1] Abdel-Rahim, Y. (2008). Khartoum-The Dream. Architects Third Scientific Conference on Urban Housing. Khartoum.

[2] Alliance of Political power in Tuti. (2007). Tuti; the Past, the present, and the future we want. Khartoum.

[3] Antrop, M. (2004). Landscape change and the urbanization process in Europe. Landscape and Urban Planning, 67(1-4), 9-26. https://doi.org/10.1016/S0169-2046(03)00026-4

[4] Bahreldin, I. Z. (2003). Revitalization of Khartoum Waterfront; Urban Design Study of Khartoum Riverside. Master Thesis, Katholieke universiteit leuven.

[5] Bahreldin, I. Z. (2013). A Critical Evaluation of Public Participation in the Sudanese Planning Mandates. University of Khartoum engineering journal (UofKEJ), 3(2), $40-46$.

[6] Bahreldin, I. Z. (2020). Rethinking Contemporary Public Spaces in Khartoum; the sit-in space invention and appropriation in Sudan's December Revolution 2018. International Seminar: "Public Space, Public Sphere, and Publicness in the Middle East." Cairo: Center for Islamic Studies Sophia, Working Paper Series.

[7] Bahreldin, I. Z., \& Hamid, G. M. (2018). Khartoum in the eyes of the youth, an alternative vision for the city of Khartoum (in Arabic). Journal of Urban Research, 12018(27), 103-116.

[8] Bruttomesso, R. (2006). Waterfront development: A strategic choice for cities on water. Paper presented at the Waterfront Development Forum: China Maritime (02 March 2006), Hong Kong.

[9] Carta, M., \& Ronsivalle, D. Eds. (2016). The fluid city paradigm: waterfront regeneration as an urban renewal strategy. Springers.

[10] El-Kheir, O. M. (1991). Unauthorized Settlements in Greater Khartoum (M. E. A. Sin \& H. R. J. Davies, Eds.). Khartoum University Press.

[11] Franck, A. (2016). Urban Agriculture Facing Land Pressure in Greater Khartoum - The Case of New Real Estate Projects in Tuti and Abu Se' id. Sudanese Institute of Architects (SIA)'s 4th Scientific and Professional 
Conference. Khartoum.

[12] Hafazalla, A. A. (2008). The Urban Development Planning of Greater Khartoum Copying with Urban Dynamics. In O. S. Osman, K. M. Osman, M. Mustafa, \& A. H. Osman (Eds.), Architects' Third Scientific Conference (pp. 33-48). Khartoum: Sudanese Institute of Architects (SIA).

[13] Hamid, G. M., \& Bahreldin, I. Z. (2013a). Environmental sustainability in Greater Khartoum between natural assets and human interventions. International Journal of Sustainable Building Technology and Urban Development, 4(2), 100-110. https://doi.org/10.1080/2093761X.2013.80 1804

[14] Hamid, G. M., \& Bahreldin, I. Z. (2013b). Khartoum 2030: An Alternative, Environmentally-Sensitive Vision for the Development of Greater Khartoum, Sudan. In L'architettura delle città (Vol. 3-4-5).

[15] Ibrahim, M. B., \& Davies, H. R. (1991). Tuti Island: A rural system in an Urban Locality. In M. E. A. Sin \& H. R. Davies (Eds.), The Future of Sudan's Capital region: A study in the Development and Change. Khartoum University Press.

[16] Idrees, N. I. (2008). Al-imran al-rasi al-gher mukhtat (in Arabic). Third Architects Scientific Conference in Sudan, 1-17. Khartoum: Sudanese Institute of Architects (SIA).

[17] Khartoum Structure Plan Implementation Directorate. MPPU. (2013). Khartoum Waterfront Development Strategy. Khartoum.

[18] Liu, H. (2013). Establishing local identity through planning and landscape design in urban waterfront development. Retrieved fromhttps://atrium.lib.uoguelph.ca/xmlui/handle $/ 10214 / 6673$

[19] Loures, L. (2015). Post-industrial landscapes as drivers for urban redevelopment: Public versus expert perspectives towards the benefits and barriers of the reuse of post-industrial sites in urban areas. Habitat International, 45, 72-81. https://doi.org/10.1016/j.habitatint.2014.06.028

[20] Marina d'Errico. (2015). The Tropical Utopia Khartoum: British Colony 1898-1910 eBook: Marina d'Errico: Amazon.co.uk: Kindle Store. Retrieved from https://www. amazon.co.uk/Tropical-Utopia-Khartoum-Marina-dErricoebook/dp/B0106X7Z3K

[21] Meffit and Centics. (2008). Khartoum Structure Plan 2008-2033. Khartoum.

[22] MEFFIT Consultancies. (1973). Beautification Programme of Khartoum-Second. Phase. Khartoum.

[23] Moretti, M. (2008). Cities on Water and Waterfront Regeneration: A Strategic Challenge for the Future.

[24] Mostafa, L. A. (2017). Urban and Social Impacts of Waterfronts Development, Case Study: Jeddah Corniche. Procedia Environmental Sciences, 37, 205-221.https://doi. org/10.1016/j.proenv.2017.03.035

[25] Mustafa Ahmad, A. (2000). Khartoum blues: the 'deplaning' and decline of a capital city. Habitat International, 24(3), 309-325. https://doi.org/10.1016/S0197-3975(99)00046-6

[26] Norberg-Schulz, C. (1984). Genius Loci: Towards a phenomenology of Architecture. Rizzoli International Publications, Inc, New York
[27] P. Yocom, K., Andrews, L., Faghin, N., Dyson, K., Leschine, T., \& Nam, J. (2016). Revitalizing urban waterfronts: identifying indicators for human well-being. AIMS Environmental Science, 3(3), 456-473. https://doi.org/10.3 934/environsci.2016.3.456

[28] Pereira, P. (2016). Rethinking public spaces in waterfront areas: Notes from Lisbon. Research in Urban Sociology, 15, 319-344. https://doi.org/10.1108/S1047-00422016000001 5013

[29] Refaat, M. H. (2015). Urban architecture for sustaining the local identity of cultural landscapes: A study of waterfront development in Khartoum, 4(1), 29-59.

[30] Sairinen, R., \& Kumpulainen, S. (2006). Assessing social impacts in urban waterfront regeneration. 26, 120-135. https://doi.org/10.1016/j.eiar.2005.05.003

[31] Tolnai, G. (2018). Budapest's fragmented riverfront renewal: Western trends interspersed with post-socialist characteristics. Belgeo, (4). https://doi.org/10.4000/belgeo. 21210

[32] Waley, P. (2007). Tokyo-as-World-City: Reassessing the Role of Capital and the State in Urban Restructuring. Urban Studies, 44(8), 1465-1490. https://doi.org/10.1080/004209 80701373511

[33] Wit, P. V. De. (2008). Land Policy Development in Post Conflict Sudan. World Bank, (1997), 1-29.

[34] Wrenn, D. M. (1983). "Urban waterfront development." Washington, D.C.: The Urban Land Institute. 